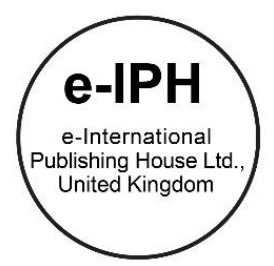

\title{
The Utilisation of LEGO and Other Materials as Prototyping Tools in the Co- Creation Process
}

\author{
Siti Salwa Isa' ${ }^{1}$ Andre Liem², Abu Ali', Siti Suriawati Isa ${ }^{3}$ \\ ${ }^{1}$ Faculty of Art \& Design, Universiti Teknologi MARA, 40450, Shah Alam, Selangor, Malaysia \\ 2 Department of Design, Norwegian University of Science and Technology, Kolbjørn Hejes vei 2B, Trondhiem, Norway \\ ${ }^{3}$ Department of Recreation \& Ecotourism, Faculty of Forestry, UPM, 43400, Serdang, Selangor, Malaysia \\ Email of All Authors: sitisalwa@ uitm.edu.my; andre.liem@ntnu.no; abuali@ uitm.edu.my; ssuria4@upm.edu.my; rafeahl@uitm.edu.my \\ Tel of 1 st Author: +60138017304
}

\begin{abstract}
This paper aims to investigate the usefulness of LEGO and other materials as prototyping tools in the co-creation process involving multiple stakeholders. The results demonstrate that using LEGO and other materials as prototypes in the co-creation process helps designers and stakeholders to explore, evaluate and modify ideas three-dimensionally to validate design solutions, idea generation and evaluation. This study believes that LEGO and other materials are efficient co-design prototyping tools to ensure its main purpose for team and strategy building in enhancing participant's ability to deliver more contribution during group discussions.
\end{abstract}

Keywords: Co-creation; prototyping tools; prototypes; LEGO

eISSN: 2398-42870 2020. The Authors. Published for AMER ABRA cE-Bsby e-International Publishing House, Ltd., UK. This is an open access article under the CC BYNC-ND license (http://creativecommons.org/licenses/by-nc-nd/4.0). Peer-review under responsibility of AMER (Association of Malaysian Environment-Behaviour Researchers), ABRA (Association of Behavioural Researchers on Asians) and cE-Bs (Centre for Environment-Behaviour Studies), Faculty of Architecture, Planning \& Surveying, Universiti Teknologi MARA, Malaysia.

DOI: https://doi.org/10.21834/ebpj.v5iSl3.2548

\subsection{Introduction}

It is essential for users to have a direct touch with product development, particularly in the early stage to boost product quality (Nonaka and Takeuchi, 1995; Zaltman, 2003; Wolf, 2014). The advantages of using direct engagement as part of the process are gauging better opportunities to access user's insight, according to Nonaka and Takeuchi (1995). Despite the frequent investigation carried out to test techniques in user involvement as an effort to increase user's knowledge, studies on user-designer collaboration are still limited. Even though user's direct involvement in the process does not necessarily offer a positive outcome, it is still considered as an efficient technique for designers to obtain first-hand information particularly matters on user's knowledge and requirement during the early phase of design development. To ensure that the involvement of users as part of the designing process runs smoothly, designers use a variety of tools and guidelines to improve co-creation practise (Sanders \& Stappers, 2014; Prahalad \& Ramaswamy, 2013; Ali \& Liem, 2015). Despite that being said, it is still hard for designers to comprehend such user involvement concept as part of their studies. It is because the involvement users will not contribute to a positive impact without the help of sufficient methods, techniques and tools. Among the main advantages of co-creation with future users or stakeholders is designers will get a precise judgement of user's wants and needs as a validation of user requirements (Sanders \& Stappers, 2014; Wolf, 2014). At present, designers and researchers are still searching for a suitable way on how to enable people to contribute efficiently in the initial design phase. It is still unsure as to which adapted design tools and techniques help to ensure the smoothness of the procedure. This is so as the classical design tools such as CAD modelling and sketching are no longer desirable as their application requires training

eISSN: 2398-4287@ 2020. The Authors. Published for AMER ABRA cE-Bsby e-International Publishing House, Ltd., UK. This is an open access article under the CC BYNC-ND license (http://creativecommons.org/licenses/by-nc-nd/4.0). Peer-review under responsibility of AMER (Association of Malaysian Environment-Behaviour Researchers), ABRA (Association of Behavioural Researchers on Asians) and cE-Bs (Centre for Environment-Behaviour Studies), Faculty of Architecture, Planning \& Surveying, Universiti Teknologi MARA, Malaysia.

DOI: https://doi.org/10.21834/ebpj.v5iSI3.2548 
(Goldschmidt and Rodgers, 2013; Isa \& Liem; 2014). Hence, this paper investigates the relevance of using LEGO and other materials in the early design phase for co-creation with future users and stakeholders in terms of applicability as a prototyping tool. Even so, only a handful number of studies have been conducted on prototyping processes and their ancillary methods for practising designers in the co-creation process. This has then resulted to the lack of existing literature vis-à-vis the rationale and the effectiveness of prototypes as tools in augmenting the creativity of designers engaging with the stakeholders (Jensen, Elverum \& Steinert, 2017; Isa \& Liem, 2014). This study aims to investigate how effective and valuable LEGO and other materials are as support tools in early idea and concept generation. Furthermore, it explores how designers' perceive and experience prototyping in a different context with stakeholders. The following research question has surfaced form literature study: RQ1; How do LEGO and other materials function as prototyping tools in assisting designers in communicating ideas with stakeholders in the early ideation process?, RQ2; Do LEGO and other materials help designers and stakeholders to develop a clearer understanding of problem-solving, function and construction?

\subsection{Method}

To gain in-depth knowledge about designers' experience in early conception and development, involving prototypes with stakeholders (Kristiansen \& Rasmussen, 2014; Harn \& Hsiao, 2018), this study utilises the LEGO Serious Play (LSP) approach. This method has been used to facilitate thinking, communication and problem-solving technique for organisations, teams and individuals. Introduced by Robert Rasmussen in 1999, LSP was developed as the strategy building tool for Lego Company. Since then, LSP has gone through some refinement in improving the techniques in making sure it fits with today's modern era. Proven for its efficiency, LSP is now opted widely by many organisations (Robertson \& Breen, 2013; Kristiansen \& Rasmussen, 2014; Wolf, 2014). This approach was chosen because participants will be guided by facilitators, who will ask questions. Using their very own creativity, participants will answer the questions by building Lego models with our the existence of any boundaries. One of the interesting aspects of LSP is that there is no right or wrong answer throughout the product development process. The flexibility of this approach makes it possible to be applied in various disciplines, including engineering, healthcare and sociology research.

To find out how LEGO and other materials enhance stakeholders' and designers' creativity in the early design process, a cocreation workshop was conducted. A research-through-design approach was used in this co-creation workshop since this study involved creativity, visual activities and modelling activities (Creswell, 2012). According to Zimmerman (2007), research through design method is appropriate to be used during generative research because it has been identified as participatory in nature, to entail creative engagement and outcome, and mainly applies to design research. This method will allow the researchers to gain new knowledge by understanding the act of making from participants, who were having responsibilities to produce creative outputs for this study (Harn \& Hsiao, 2018; Zimmerman, 2007; Creswell, 2012). The data collection and analysis method developed in this study was adapted from Goldschmidt and Rodgers, (2013) and Dow et al., (2009). Facilitators kept observation notes and took pictures during the whole design process. However, the researcher concentrated mainly on a specific segment of the data as well as relevant expert reviews. The data were analysed by reviewing audio and video recordings, field notes and photographs in the design practice. Using multiple data collection methods in different perspectives were captured in this study.

\subsection{Workshop arrangement}

The workshop comprised four sessions (see figure 1). Three of these sessions addressed the creative development, where each session dealt with different tasks. In session 1, the workshop started with a short presentation of the study and a briefing session regarding processes and procedures. After that, the participants were asked to complete a form to record their background information as well as to sign a consent form to agree to participate in this study. Then the researcher briefly explained the aim of the project rules and regulations. According to the project briefing, all participants had the task to co-create a new solution for a better service and experiences in Museum Pahang. They need to prototype their ideas by only using LEGO and other materials. After the briefing session, the participants were randomly divided into four groups (8 participants from multiple backgrounds and two professional designers in one group), and each of the groups went through a sequence of activities as shown in figure 1.

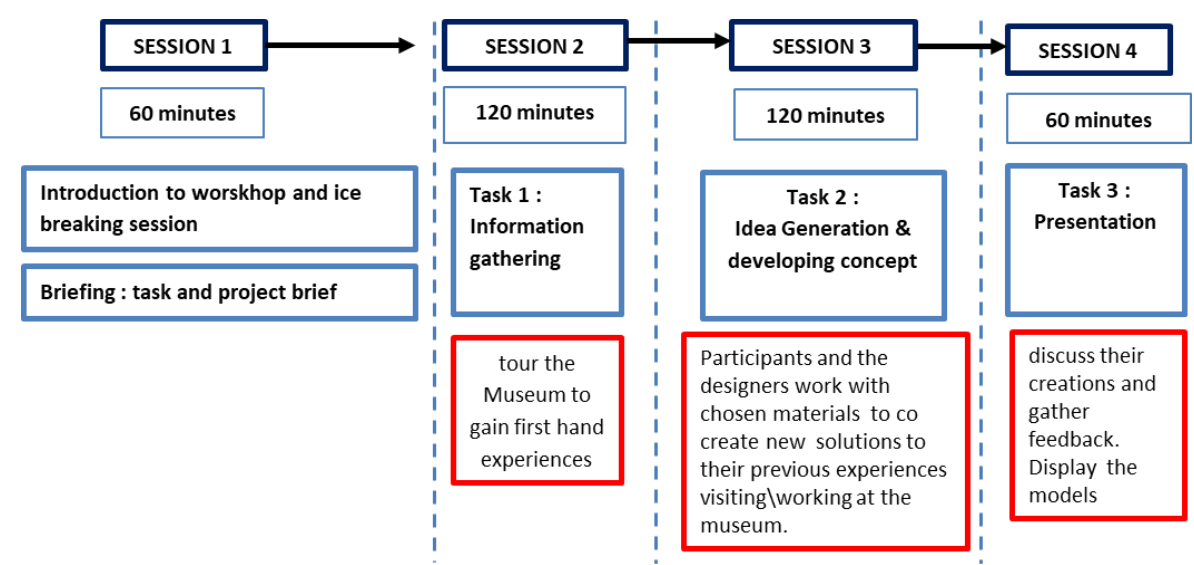

Fig. 1. Creative Workshop sessions during the study. 


\subsection{Participants selection}

40 participants, comprising 8 professional designers, 12 museum workers and 20 stakeholders (museum visitors: postgraduate students, lecturers, general workers) took part in the co-creation workshop. All participants were randomly invited without them knowing what they would have to do during the session. The purpose was to elicit spontaneity during the session, which required participants to be unprepared. The total number of participants were 14 male and 26 female participants. Their age range was between 22 - 35 years old. Participation was voluntary.

\subsection{Workspace, facilities and materials}

The design workshop was conducted in four meeting rooms at Lembaga Muzium Negeri Pahang, Pekan Pahang Malaysia. Participants were divided into groups, and the arrangement was set up following a discussion classroom format. As shown in table 1. diverse range of materials and tools were provided to facilitate idea development throughout the stages. The other materials were chosen based on low fidelity materials for prototyping purpose that can be used with necessary tools while making. Table 1 gives an overview of these tools and materials according to the assigned tasks.

Table 1. Tools and materials are given to the participants during the activities.

\begin{tabular}{|l|l|l|l|}
\hline & Tools & LEGO & Other Material \\
\hline Building Task & $\begin{array}{l}\text { Pencil, pen and marker, } \\
\text { Cutter, Scissors, Masking } \\
\text { tape, Glue }\end{array}$ & $\begin{array}{l}\text { LEGO bricks, LEGO parts, LEGO mini figures, } \\
\text { Loxboard, mounting board, rope, modelling clay, } \\
\text { sticks, decorative sticks, stickers, ice-cream } \\
\text { sticks, wire, foam, straw, sponge }\end{array}$ \\
\hline
\end{tabular}

\subsection{Results and Discussion}

Findings were classified and discussed based on two main parts. In the first part, the participants' design output evaluation of the ideas was discussed according to the process of implementing physical prototypes in the concept development. To assess the participant's idea, researchers conducted a heuristic evaluation of the raw workshop data. Two criteria were identified for evaluation; innovativeness of the ideas and problem-solving quality. These characteristics were important to measure the ideas, relative to the use of LEGO and other materials as physical prototypes. Concerning the heuristic evaluation, results were discussed according to the group. In the second part, group summarise analysis were addressed to how they use LEGO and other materials as physical prototypes in the co-creation process.

\subsection{Participants' design output evaluation}

This section presents the observations results from the participant's workshop activities as well as the contextual inquiries during the process, the output of the co-creation process using LEGO and other materials as prototyping tools and group presentation on their creation. The findings were discussed according to the process, materials use and exploration of what was being delivered at typical stages of the process.

\subsection{Group 1}

In the early stage, the participants explored ideas more holistically, emphasising on existing service and user experience at the museum. This implies that these participants, through past experiences, have implicit knowledge about internal issues, services and experiences compatibilities, and therefore do not feel the need to elaborate on these aspects at this stage explicitly. For this group, the more abrupt transition from holistic to the concrete development of ideas can be seen during the prototyping development stage. They showed more detailed constructions, and we're able to think through more iterative discussion while making and were more reflective about generating new design solution through prototyping. It appears that participants and professional designers were comfortable with using LEGO and other materials as prototyping tools, which can be seen in the problem-solving quality and innovativeness of the ideas through their prototypes. See Figure 2 below.

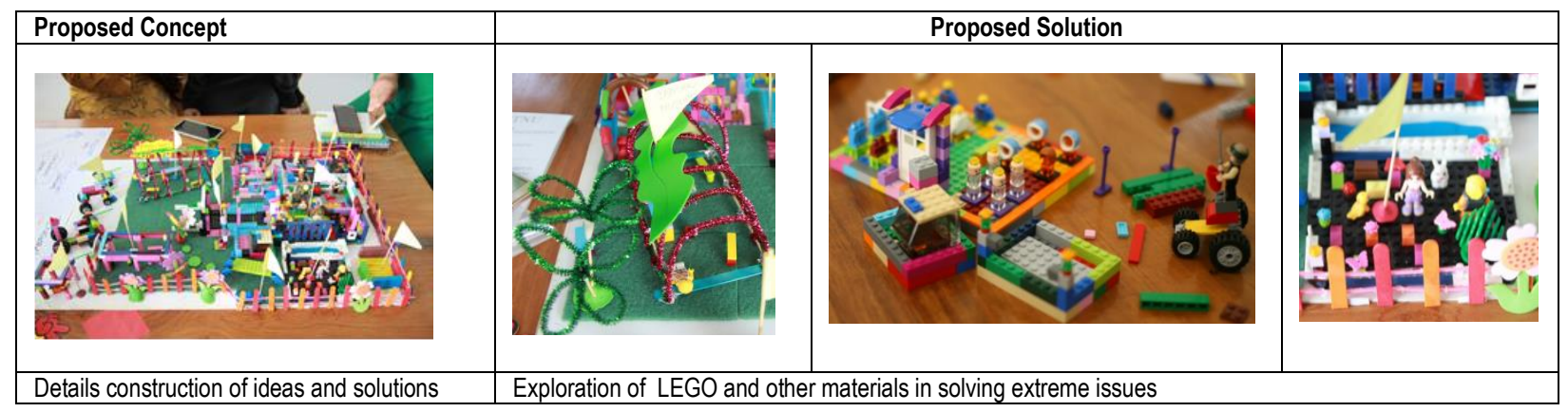

Fig. 2. Group 1 final design output. 


\subsection{Group 2}

This group showed a greater exploration in ideas in terms of the possibility to construct, explore a new solution, and play in a handson manner by interacting with modelling materials. The use of LEGO and other materials to prototype problem solutions and new ideas were developed during the co-creation process. Furthermore, the use of prototypes in the process did show a significant exploration of ideas and created fruitful discussion among the participants to build better solutions to the experiences. From the complete representation, it can be concluded that LEGO and other materials may have the flexibility as prototyping tools to enhance the creative space in co-creation activities. Participants also came up with ideas and solutions by building a metaphorical model from LEGO. See figure 3 below.

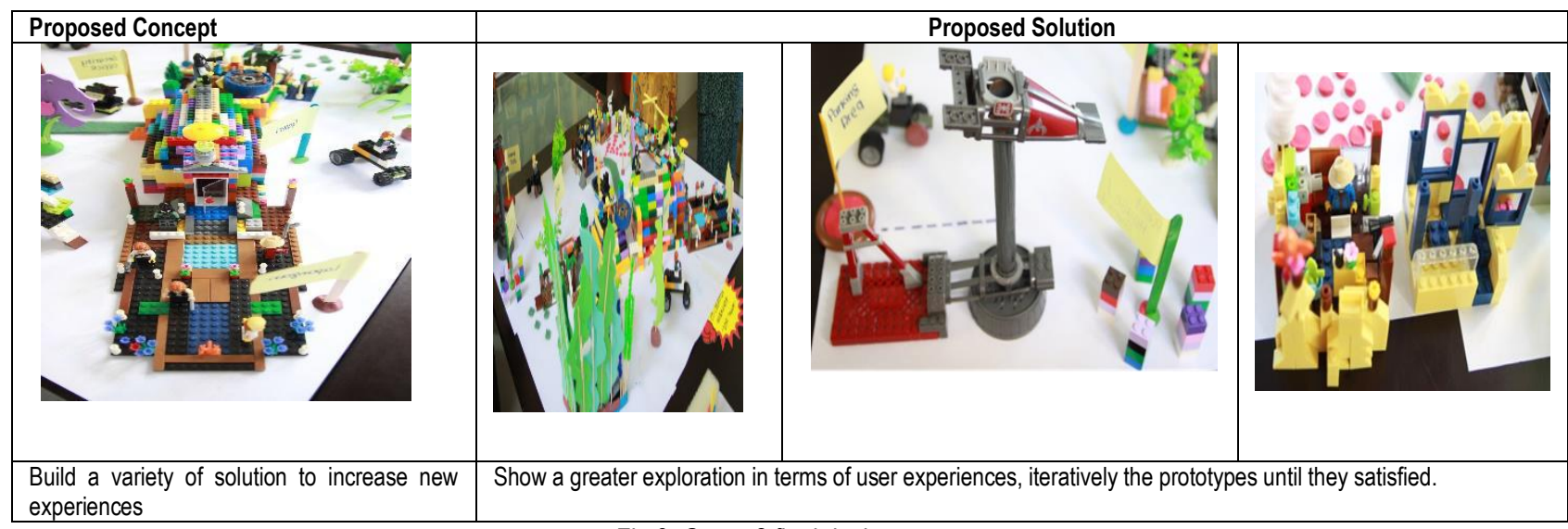

Fig.3. Group 2 final design output.

\subsection{Group 3}

This group created ideas with multiple design solution when using LEGO and other materials as prototypes in the early idea stages. This is evident through clearly defined problem solving, elaborated carefully on what was created using prototypes during the cocreation process. During the development staged, they emphasised more on user new experiences by exploring the flexibility in generating ideas using LEGO and other materials as prototypes whereas surprisingly, significantly contributed in creative problem solving and detailing on the proposed concept. See figure 4 below.

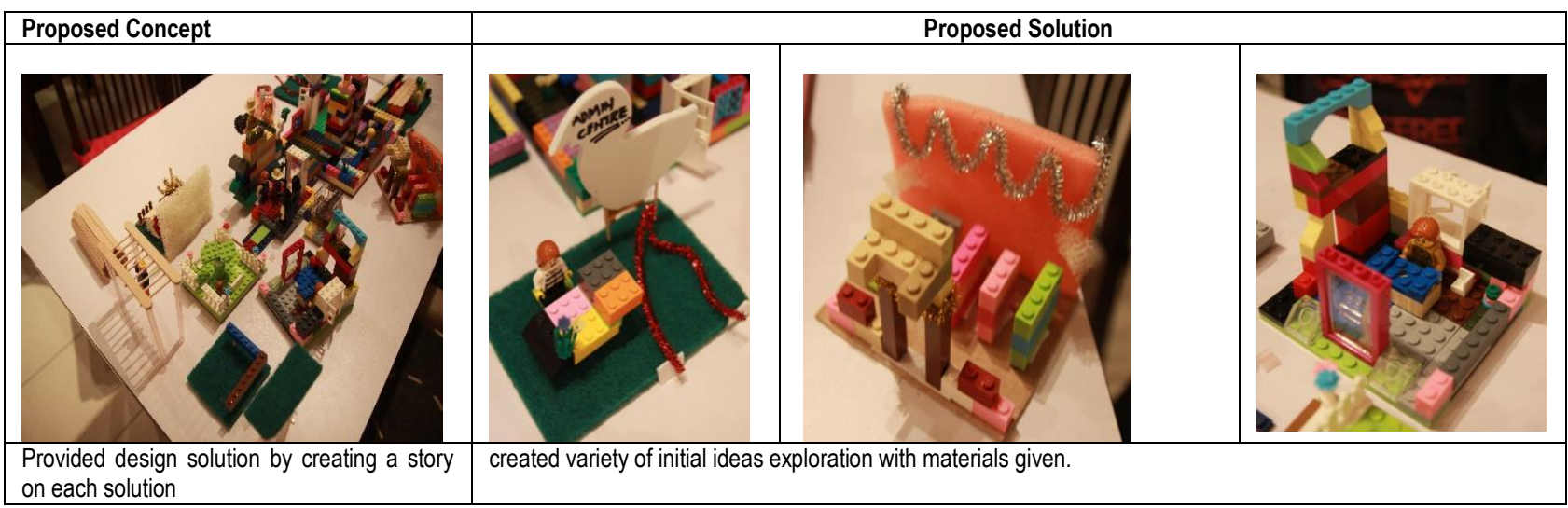

Fig.4. Group 3 final design output.

\subsection{Group 4}

During the early development stage, they produced rough and basic ideas with the exploration of LEGO only. They used LEGO to explore in the early idea stage but focused less on the detailing in the development process. Only some of the materials given were explored to produce ideas, construction and problem solution of the designs. In the development stage, the exploration of ideas using other materials was very limited, as participants either possessed limited knowledge of the project or were not interested. They only focused on geometric ideas using LEGO. At the same time, prototyping and were not able to detail their ideas using other visualisation materials, and their exploration in prototyping itself was somewhat limited. Newly introduced materials were not used so much in their prototyping activities maybe because they became too comfortable with the LEGO system that was flexible and durable to represent and communicate the actual design intent clearly and neatly. However, this does not limit their attitudes towards exploring new ideas. See Figure 5 below. 


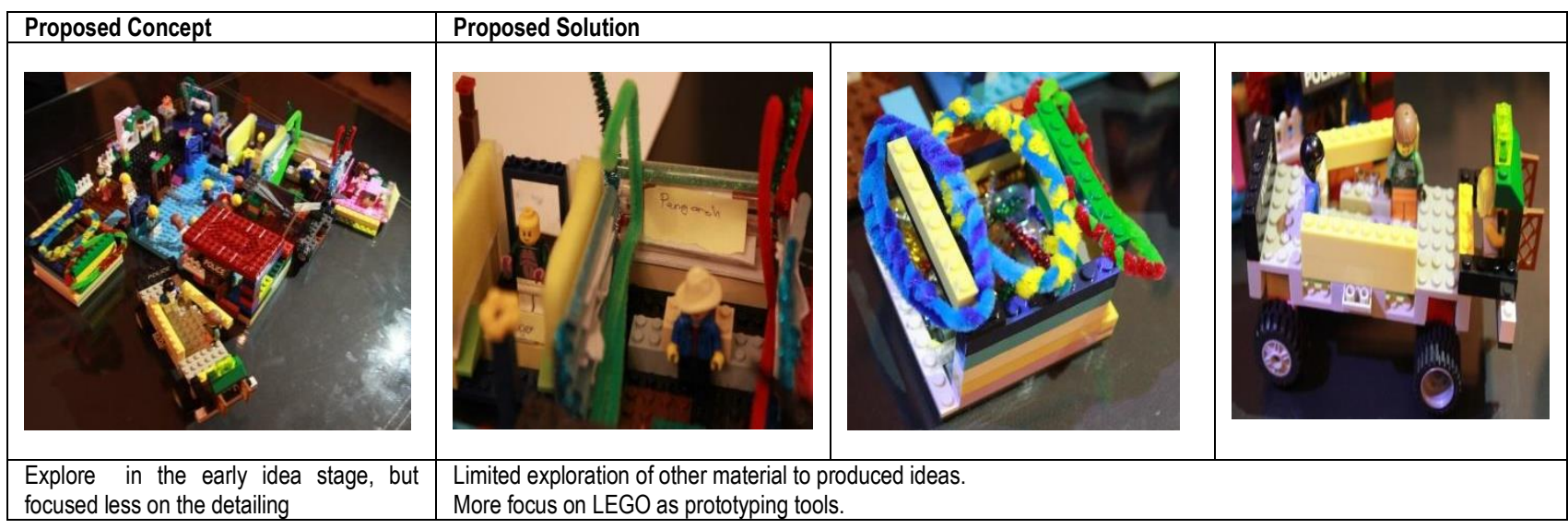

Fig.5: Group 4 final design output.

\subsection{Group summarise the analysis}

Table 2, summarises and compares group exploration towards idea generation using LEGO and other materials in the co-creation processes. Group 1, 2 and 3 showed preferences for LEGO and other materials as prototyping tools when compared to Group 4, which only focussed more on LEGO instead of other materials as prototyping tools for idea generation. This result is interesting for this research to expand further on the factors that contribute to the outcome. With reference to prevailing design behaviours, attitudes and mindsets among the participants, each of the materials given has their strengths and weaknesses with respect to how they are being applied and how they contribute to each of the stages in the design process. Notably, all participants valued the contribution of LEGO and other materials as prototyping tools for the design development process, because it facilitates divergent and convergent exploration of ideas, as well as more accurate evaluation of the design through interactions with the prototype/model. In the idea development stage using prototypes, majority of the participants only explored with the materials that were provided and familiar to them, which were mainly cardboard, clay modelling and wooden sticks. From the contextual inquiries, the majority of the participants agreed that prototyping was instrumental in determining the level of innovativeness, problem-solving, and qualities of their ideas. The use of LEGO and other materials to prototype also serves as mechanisms to provide a better understanding of user experiences, needs and values as well as to continuously engage other stakeholders in the discovery and development of new ideas and concepts. Furthermore, the nature of low fidelity material provided in this study that is tangible, rough and incomplete in appearance leads the participants to feel dissatisfied with their ideas and make them always refine the ideas to create a better form and iteratively testing them out to study the function and construction of their ideas.

Table 2: Comparison between each group design output for the co-creation activities.

\begin{tabular}{|c|c|c|c|c|}
\hline Process & Group 1 & Group 2 & Group 3 & Group 4 \\
\hline Idea generation & $\begin{array}{l}\text { - solve design problems } \\
\text { - } \text { speculate design outcome } \\
\text { - Mainly produced rough ideas } \\
\text { through empathy and needs } \\
\text { - explores more holistically }\end{array}$ & $\begin{array}{l}\text { - show a greater } \\
\text { exploration in terms } \\
\text { of user experiences } \\
\text { - build solutions to } \\
\text { the experiences }\end{array}$ & $\begin{array}{l}\text { - Produced a variety of } \\
\text { construction with the basic form } \\
\text { of ideas } \\
\text { - use of various materials } \\
\text { - created variety of initial ideas } \\
\text { exploration with materials given. }\end{array}$ & $\begin{array}{l}\text { - produce rough ideas only } \\
\text { - play around with shape and } \\
\text { form } \\
\text { - limited in divergence detailed } \\
\text { in terms of ideas and } \\
\text { construction }\end{array}$ \\
\hline $\begin{array}{l}\text { Exploration of } \\
\text { LEGO and other } \\
\text { materials }\end{array}$ & $\begin{array}{l}\text { - Prototyping with board and } \\
\text { sticks } \\
\text { - Change ideas through } \\
\text { prototyping } \\
\text { - Experiment with various } \\
\text { materials } \\
\text { - explored a lot of multiple } \\
\text { shape and form }\end{array}$ & $\begin{array}{l}\text { - Using prototypes } \\
\text { as a tool to explain } \\
\text { and explore the } \\
\text { ideas } \\
\text { - Change and } \\
\text { refinement using } \\
\text { LEGO and other } \\
\text { materials }\end{array}$ & $\begin{array}{l}\text { - Limited exploration of shape and } \\
\text { construction } \\
\text { - no amount of flexibility in ideas } \\
\text { - use of various materials but has } \\
\text { not shown significant leverage of } \\
\text { exploration }\end{array}$ & $\begin{array}{l}\text { - used only LEGO as a tool to } \\
\text { explain the design } \\
\text { - another type of material is not } \\
\text { explored widely }\end{array}$ \\
\hline
\end{tabular}

\subsection{CONCLUSION}

The main objective of this study is to develop a co-creation tool which could be used regardless of where and when the design process happens. As the outcome from it, LEGO mixes with other low fidelity materials to prototype is less time consuming and does not require much components and templates in comparison to high fidelity materials which however is suitable for prototyping sophisticated in product design. They will assist designers in evaluation, experimentation and co-creation, by distributing them to nondesigners to imagine future objects, future experiences and future ways of living. The underlying basis on the idea of constructionism by Papert (Papert, 1980) highlights that actively building things with hands improves thinking and learning. 


\section{References}

Ali, A., \& Liem, A. (2015). The use and value of different co-creation and tolls in the design process. In DS 80-3 Proceedings of the 20th International Conference on Engineering Design (ICED 15) Vol 3: Organisation and Management, Milan, Italy, 27-30.07. 15.

Creswell, John W.(2012). Qualitative inquiry and research design: Choosing among five approaches. Sage, 2012

Dow, Steven P., et al. "Parallel prototyping leads to better design results, more divergence, and increased self-efficacy." ACM Transactions on Computer-Human Interaction (TOCHI) 17.4 (2010): 18.

Goldschmidt, G. and Rodgers, P.A.(2013). The design thinking approaches of three different groups of designers based on self-reports. Design Studies 34. (2013). Pp $454-471$

Harn, P. L., \& Hsiao, C. C. (2018). A Preliminary Study on LEGO®-Based Workplace Stress Reduction with Six Bricks and LEGO® SERIOUS PLAY® in Taiwan. World Journal of Research and Review, 6(1), 64-67.

Isa, S. S., and A. Liem. (2014). "CLASSIFYING PHYSICAL MODELS AND PROTOTYPES IN THE DESIGN PROCESS: A STUDY ON THE ECONOMICAL AND USABILITY IMPACT OF ADOPTING MODELS AND PROTOTYPES IN THE DESIGN PROCESS." DS 77: Proceedings of the DESIGN 2014 13th International Design Conference. 2014.

Isa, Siti S., and Andre Liem. (2014). "Enhancing Design Sensitivity and Creativity in the Detailing and Materialisation Stages of the Design Process through Specific Models and Prototypes." DS 81: Proceedings of NordDesign 2014, Espoo, Finland 27-29th

Jensen, M. B., Elverum, C. W., \& Steinert, M. (2017). Eliciting unknown unknowns with prototypes: Introducing prototrials and prototrial-driven cultures. Design Studies, $49,1-31$.

Kristiansen, P., \& Rasmussen, R. (2014). Building a better business using the Lego serious play method. John Wiley \& Sons.

making in co-designing, CoDesign: International Journal of CoCreation in Design and the Arts, 10:1, 5-14, DOI: 10.1080/15710882.2014.888183

Nonaka, I., \& Takeuchi, H. (1995). The Knowledge-Creating. New York, 304.

Papert, S. (1980). Mindstorms: Children, computers, and powerful ideas. Basic Books, Inc

Prahalad, C. K., \& Ramaswamy, V. (2013). The future of competition: Co-creating unique value with customers. Harvard Business Press.

Robertson, D., \& Breen, B. (2013). Brick by brick: How LEGO rewrote the rules of innovation and conquered the global toy industry. Crown Business

Sanders, E. B. N., \& Stappers, P. J. (2014). Probes, toolkits and prototypes: three approaches to making in co-designing. CoDesign, 10(1), 5-14.

Wolf, M. J. (2014). LEGO Studies: Examining the Building Blocks of a Transmedial Phenomenon. Routledge.

Zaltman, G. (2003). How customers think: Essential insights into the mind of the market. Harvard Business Press.

Zimmerman, John, Jodi Forlizzi, and Shelley Evenson. (2007) "Research through design as a method for interaction design research in HCl." Proceedings of the SIGCHI conference on Human factors in computing systems. ACM, 2007. 